\title{
An Acoustic and Phonological Study of Pre-Pausal Vowel Length in Hausa
}

\author{
ROXANA MA NEWMAN and VINCENT J. VAN HEUVEN
}

\section{INTRODUCTION}

In Hausa, vowel length is maximally contrastive in word-final position, where all five vowels occur lexically both long and short. In describing the phonetic differences between long and short final vowels, one has to specify whether the vowel is in pre-pausal position or not. In non-pausal position, final vowels have essentially the same allophones as medial vowels, where the length contrast is manifested qualitatively as well as quantitatively: long vowels are long and tense whereas short vowels are shorter, lax, and more centralized, e.g.,

(1)

Long
tsakaa cèe $\quad$ [tsıka:...]
'It's a gecko'
zoobèe nee $\quad$ [zo:bè:...]
'It's a ring'
tukkuu nèe $\quad$ [tukku:...]
'It's a bird's crest'

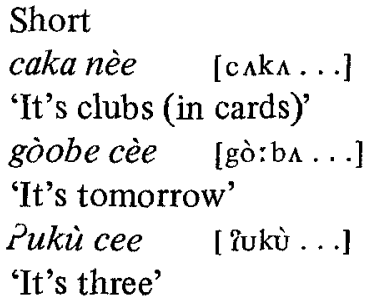

In pre-pausal position, the difference between long and short final vowels is not so evident; both are tense and the difference in duration is said to be quite reduced (Greenberg 1942:320). Carnochan (1951:103839) observed that the most prominent feature differentiating pre-pausal short from long vowels was the presence of glottal closure and release in the former vs. its absence in the latter, which was often marken by breathy release. ${ }^{1}$

*A shorter version of this paper was presented at the Twelfth Annual Conference on African Linguistics, Stanford University, April, 1981, and at the Hausa Workshop, School of Oriental and African Studies, London, May, 1981. We would like to thank Abdulhamid Abubakar, Bello Ahmad Salim and Fatimah Salim for their assistance in providing the Hausa data on which this paper is based. 
$\begin{array}{llll}\text { (2) Long } & & \text { Short } & \\ \text { tsakaa } & \text { [tsıka:] } & \text { caka } & \text { [cıka?] } \\ \text { zoobée } & \text { [zo:bè:] } & \text { gòobe } & \text { [gò:be?] } \\ \text { tukkuu } & \text { [tukku:] } & \text { Pukù } & \text { [?ukù?] }\end{array}$

In addition to its lexical function, the world-final length contrast in Hausa is used for marking inflection and derivation. Such morphosyntactically conditioned length alternations may result from either shortening or lengthening processes. A typical example of shortening is the derivation of a proper name from a common noun (see 3a), and a typical example of lengthening is the formation of a present participle from a verb (see $3 b$ ).

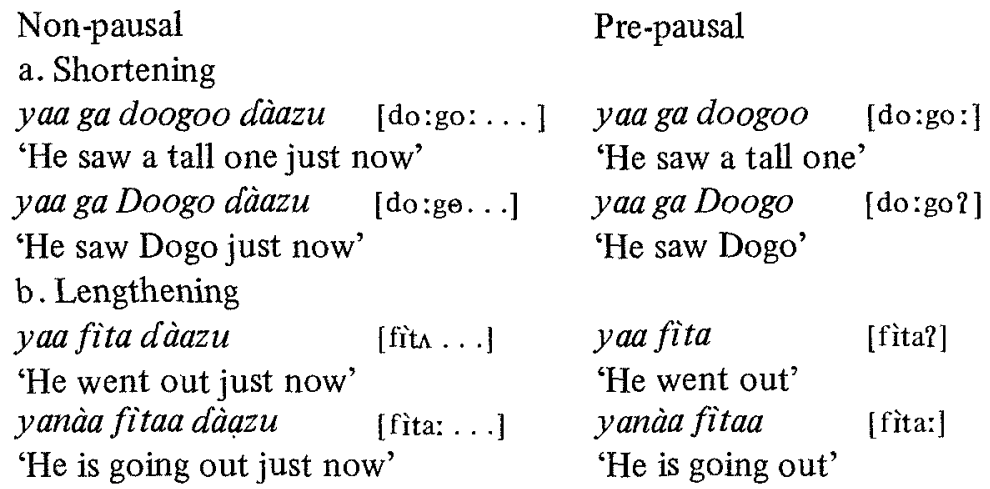

Although pre-pausal glottal closure has been generally accepted as the defining characteristic of short final vowels and the major phonetic/ auditory cue for identifying them, the actual practice of Hausa scholars in determining final vowel length has been to elicit forms in non-pausal frames. This was explicitly recommended by Gouffé (1965) and adopted in the preparation of the most recent Hausa dictionary (Newman and Newman 1977). This method works well because, as seen in (1), long and short final allophones are maximally differentiated in non-pausal position. But the method is workable only because it is assumed that phonological length remains constant irrespective of position before pause or not. On the whole, this is true in Hausa.

\section{THE PROBLEM}

There are, however, a number of poorly understood cases where a final vowel seems to have one length non-pausally and another length prepausally, exhibiting what appears to be an environmentally conditioned alternation. Specifically, these are cases where the final vowel is clearly long in non-pausal position but is reported to be pronounced with final 
glottal closure in pre-pausal position, i.e. having the normal mark of a short final vowel in this position, as in the following example from Carnochan (1952:89):

$\begin{array}{lll}\text { Non-pausal } & & \text { Pre-Pausal } \\ \text { yaa cikoo tìuluu } & \text { [crko:...] } & \begin{array}{l}\text { yaa cikoo } \\ \text { 'He filled (it)' }\end{array}\end{array}$

It is not clear whether such pre-pausal vowels are actually the same phonetically as normal short final vowels nor what their phonological status is.

Provisionally, we will refer to these vowels as "undetermined" final vowels to distinguish them from normal long and normal short final vowels. In the cases where long and "undetermined" alternate, no change of grammatical information is involved, so that the alternation seems to be strictly conditioned by the phonological environment. If these "undetermined" vowels are in fact simply short vowels, then they would represent the only case in Hausa morphophonemics of a strictly phonologically conditioned length alternation of final vowels. ${ }^{2}$

Even more unusual is that this purported alternation is morphologically restricted to a small number of diverse cases. Here is a list of all known cases where such alternations have been reported. ${ }^{3}$

(5) a. Final $-A$ in first person singular pronoun, bound possessive form, e.g. gidaan $A$ 'my house', riigaat $A$ 'my gown'

b. Final - $O$ of Grade VI (ventive extension) verbs, e.g. koom $O$ 'return (here)', saat $O$ 'steal (and come)', saak $O$ 'weave (and bring)', fitO 'come out', googO 'rub (and bring)'

c. Final vowel of "monosyllabic" verbs not ending in $-i$ : $j A$ 'pull', $s h A$ 'drink', $j E$ 'go to', $s O$ 'want', $z O$ 'come'; ${ }^{4}$ biy $A$ 'pay', jir $A$ 'wait for', kirA 'call' 5

d. Final diphthongs of monosyllabic verbs: $k A I$ 'carry', $h A U$ 'climb', $k A U$ 'move away'

A review of the scholary literature and pedagogical grammars of Hausa reveals that Hausaists are far from agreeing on the existence of all these cases, let alone on their analysis and transcription. Cases (a) and (b) are the most widely known and discussed, but what is striking is that even here the same scholar often treats them differently.

\subsection{Case (a)}

Most Hausaist now accept the existence of a long/short alternation in 
the first person singular possessive pronoun. ${ }^{6}$ Abraham (1959) analyzes it as an underlying short vowel which lengthens in specific morphosyntactic environments. Kraft and Kirk-Greene (1973:47) more accurately observe that the vowel lengthening is not grammatically determined but rather occurs everywhere except before pause; but they still consider it basically short and have a lengthening rule applying whenever another word follows. Their phonemic transcription reflects this alternation. Cowan and Schuh (1976:100) turn the analysis around by treating the vowel as underlyingly long, which is said to be short before pause. Contrary to normal transcription practice, they mark the vowel as long even before pause. Gouffé (1977:382) criticizes this "morphophonemic" representation, claiming that the phonemically short pre-pausal alternant should be transcribed as such.

\subsection{Case (b)}

Unlike case (a), Hausaists do not all agree that a length alternation takes place in the final $-O$ ventive extension of verbs. This vowel has been traditionally described as being long in all environments (e.g. Abraham 1959). Carnochan's study (1952) of final vowel alternations in verbs was the first to point out that in pre-pausal position, $-O$ verbs ended with glottal closure, which for him was the mark of a short vowel. Carnochan's phonetic observation, however, was ignored by Parsons $(1960,1971 / 72)$ in his subsequent systematization of Hausa verb morphology, in which only grammatical contexts (e.g. presence or absence of direct object) were considered relevant. In Parsons' system, the final vowel of Grade VI verbs was long everywhere and transcribed as such even before pause. Other scholars, however, have incorporated Carnochan's observation to the extent that they mention a pre-pausal short or shortened variant, e.g. Kraft and Kirk-Greene (1973:239), Cowan and Schuh (1976:280), and Jungraithmayr and Möhlig (1976:134). Nevertheless, all of these grammars continue to mark it long in this position. Surprisingly, Gouffé, a normally reliable observer of final vowel length in Hausa, totally rejects the statement that the pre-pausal $-O$ is short(ened). Consistent with the Parsonian system, he insists that "le -oo ...demeure long dans tous les contextes" $(1974: 396) .^{7}$

\subsection{Case (c)}

It has been generally accepted among Hausaists that monosyllabic verbs ending in vowels other than $-i$ have a long vowel in all positions. Carnochan (1952:109), however, noted that before pause these verbs have final glottal closure; but this observation has received less acknow- 
ledgement and even less consistent treatment than in case (b). The scattered remarks found in recent grammars are characterized by vagueness as to which vowels and which verbs are involved. For example, Hodge and Umaru (1963:17) briefly note that "some long vowels are followed by a glottal stop". This is illustrated by only one verb, $j E$, which is shown as having free variation in length pre-pausally (transcribed either as $|j \bar{e} \vec{R}|$ or $/ j e P /$ ). Cowan and Schuh (1976) represent $z O$ pre-pausally as short in the early chapters of the book but long in later chapters, and make no mention of other monosyllabic verbs. Jungraithmayr and Möhlig (1976:6) note that some verbs, illustrated only by $\operatorname{sh} A$, become short before pause, yet they transcribe it as long everywhere. The disyllabic verbs biy $A$, $j i r A$, and kirA are not normally considered as part of this set, and their behavior pre-pausally is not generally known. ${ }^{8}$

\subsection{Case (d)}

Carnochan (1952:109) included $k A I$ and $h A U$ in his list of monosyllabic verbs exhibiting glottal closure in pre-pausal position. Other scholars have, on the whole, chosen to ignore this observation, most probably because of the analytical contradiction it presents. As generally conceived, final glottal closure implies a short vowel, which in this case would mean positing "short diphthongs". Such a concept has never been considered possible in Hausa for two reasons. The first is that the length distinction is not considered applicable to diphthongs, which have always been thought of, at least phonetically, as inherently long vowel nuclei. The second is that most Hausaists claim that diphthongs should be analyzed structurally as sequences of vowel + semivowel (/ay/ and /aw/) rather than as single vocalic units with complex nuclei (/ai/and /au/). Given such an analysis, it is difficult to see how the short pre-pausal variants could be handled in any way but by an ad hoc rule. (The VC analysis of Hausa diphthongs has been critically examined and rejected in a recent study by Newman and Salim (n.d.).)

\subsection{Summary of the problem}

The preceding review has shown that these four cases have been treated as isolated phenomena, unrelated to each other, resulting in confusion at the phonetic level and inconsistent treatment at the phonological level. To summarize, case (a) is generally treated as short before pause, exhibiting a morphophonemic alternation. Cases (b) and (c) are inconsistently described as "short", "shortened" and/or "having glottal closure", their structural status being left vague. As for case (d), any difference between non-pausal and pre-pausal diphthongs has been conveniently ignored. 
The question naturally arises whether these four cases do in fact exhibit the same phenomenon, and if so, whether this can lead to a phonologically consistent treatment for all the cases taken as a set. In the present study, we take it as given that all "undetermined" vowels, including diphthongs, are long in underlying structure, ${ }^{9}$ so that we are only examining their behavior before pause. In section 2 , we present a detailed acoustic comparison between undetermined vowels and normal short and long prepausal vowels. In section 3 , we provide a phonological interpretation of the undetermined vowels on the basis of the phonetic findings.

\section{THE PHONETIC QUESTION}

The accepted phonetic characterization of the contrast in Hausa between long and short pre-pausal vowels is one of long duration without glottal closure vs. short duration with glottal closure, as illustrated above in (2). If it is true that undetermined vowels do end in glottal closure - as claimed by Carnochan - does it automatically mean that they are therefore short vowels, i.e. identical and indistinguishable from normal short vowels? Or might there in fact be differences in duration between them? In principle, of course, given the variables duration and glottal closure, four (not two) possibilities exist: short duration with glottal closure, short duration without glottal closure, long duration with glottal closure, and long duration without glottal closure.

\subsection{Experimental preliminaries}

A preliminary recording of all the items in (5) by one Hausa speaker confirmed that they were indeed all pronounced with final glottal closure. The next step was to compare a selection of these with spectrally identical vowels which were indisputably long or short, examining both duration and glottal closure as separate variables for all the vowels tested. Since no experimental data exist on the measurement of Hausa vowels prepausally, a detailed experiment was carried out to establish the necessary phonetic facts. ${ }^{10}$

The acoustic parameters chosen for measurement were (i) the overall duration of the final vowels, and (ii) their abruptness of offset. It has been shown that abruptness of offset is the most important correlate of postvocalic glottal stop in French (Malécot 1975) and of isolated checked vowels in Dutch (Cohen, Slis and 't Hart 1963). Abruptness of offset is measured in terms of the duration of the final or decay portion of the vowel, i.e. the time inverval during which the vowel intensity more or less regularly decreases from full strength to silence. A vowel checked by glottal stop has an abruptly ending or steep intensity curve, whereas an 
unchecked vowel has a smoother decay time curve. Since decay time forms a part of the overall vowel duration, it follows, ceteris paribus, that a shorter decay (i.e. abrupt offset) contributes to shorter overall duration whereas a longer decay (i.e. smooth offset) results in longer overall duration.

Our experiment also provided for variation in duration along a speech rate continuum. One knows from the experimental phonetic literature that vowel (rather than consonant) durations are time compressed in fast speech (Kozhevnikov and Chistovich 1965). To our knowledge, there are no data on the effects of speech rate on the component parts of vowel duration. A naive expectation would be that duration of the initial, i.e. non-decay, portion and of the decay portion are affected to the same degree. However, it may be the case that decay times are produced in a relatively invariant manner. Motivations for such an expectation are diverse and may be sought in either physiological or perceptual mechanisms. For instance, it may be that adduction of the vocal cords, the articulatory gesture controlling glottal closure, is relatively time invariant. We do have evidence from psycho-physical measurements (van Heuven and van den Broecke 1979, van den Broecke and van Heuven 1981), that the human hearing mechanism is less sensitive to decay time differences than to other acoustic parameters relevant to speech perception. Therefore it would make sense for the speaker to vary the decay time of his abrupt vs. gradual vowels as little as possible.

\subsection{The experiment}

As can be seen in (5), all undetermined vowels have High tone. Furthermore, aside from the item $j E$ in case (c), all undetermined vowels are either $a$ or $o$, or the diphthongs $a i$ or $a u$. For the experiment, a $3 \times 4$ stimulus word matrix was constructed consisting of a three-term length factor $\mathrm{S}$ (hort), U(ndetermined), and L(ong), and a four-term vowel quality factor, $a, o, a i$, and $a u$. Each cell contained from two to four test items, except for the cells "short ai" and "short $a u$ ", which remained empty on structural grounds. Each test item consisted, whenever possible, of a disyllabic utterance with a heavy first syllable and an initial voiceless stop in the second syllable. The items were further confined to two tone patterns, Low-High and High-High, to ensure comparability with the High tone undetermined vowels.

\subsubsection{Method}

The resulting list of 26 items (see Appendix 1) was recorded in a sound attenuating booth (Amplaid GR-12) onto a Revox A77 two-track tape recorder $(19 \mathrm{~cm} / \mathrm{sec})$ with a Sennheiser MD421 microphone by two different speakers, male and female, 
of the same age, speaking the standdrd Kano dialect of Hausa The set of 26 1tems, each embedded in a Hausa carrer phrase (dagà baaya, ta cèe "Afterwards, she said '), was recorded 10 times per speaker in different random orders, five times at a relatively slow speaking rate and five times at a relatively fast but comfortable speaking rate The response set of the experiment thus consisted of a total of 520 vowel tokens

Both the audiosignal and the intensity (Frokjær-Jensen IM360 intensity meter, full bandwidth, $20 \mathrm{~ms}$ integration time) were then recorded on UV oscillograms (Honeywell 2206 Visicorder, $20 \mathrm{~cm} / \mathrm{sec}$ ) for each of the 520 tokens Final vowels were segmented in terms of an initial portion comprising rise time and steddy time, and a final portion containing the decay time In our experiment, decay time was operationally defined (cf Debrock 1977) as the time needed for the vowel intensity (in $\mathrm{dB}$ ) to drop from $90 \%$ to $10 \%$ of the highest value attaned in the vowel Overall duration was equal to the sum of the initial and tinal portions All measurements were rounded off to the nearest $5 \mathrm{~ms}$ The procedure is lllustrated in Figure 1

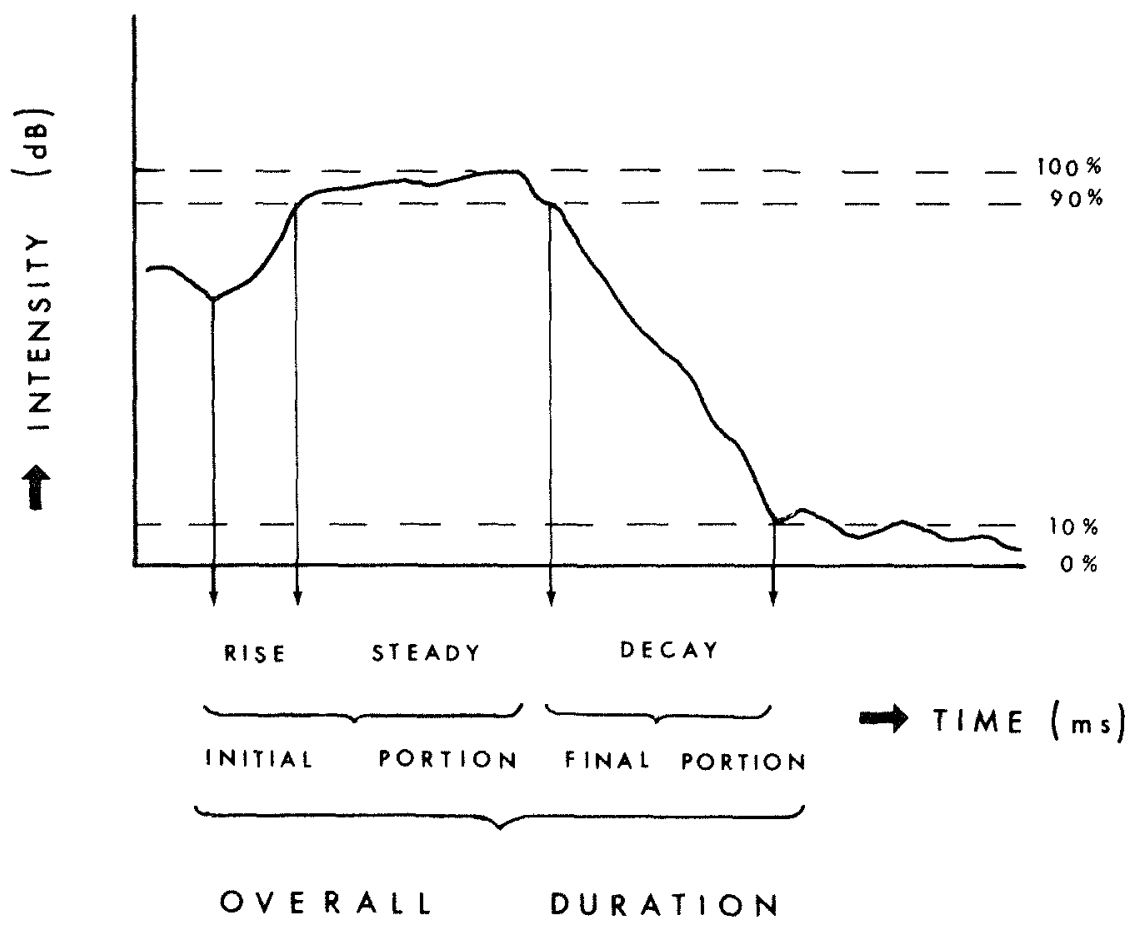

Figure 1 Procedure for measuring components of final vowel duration from vowel intensity

\subsection{Results}

The mean total durations and standard deviations are presented in I igure 2 (See Appendix 2 for a complete breakdown of the data) Each of the four vowel 


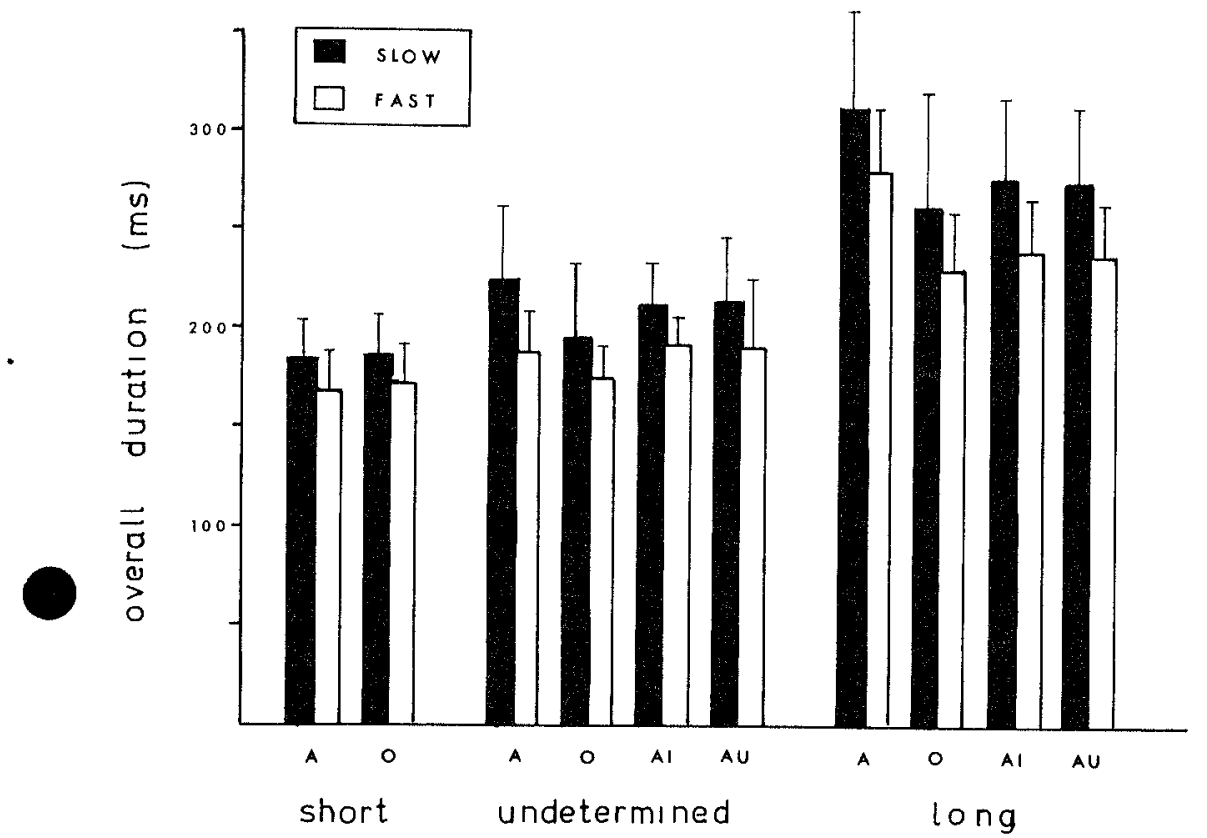

Figure 2 Mean overall durations $\pm 1 \mathrm{~s} \mathrm{~d}$ for short, undetermined, and long prepausal vowels at slow and fast speech rates

qualities has been plotted separately for the three phonetic length groups and for slow (shaded) vs fast (unshaded) speech conditions

It can be clearly seen that the $L$ vowels form a group together (mean $263 \pm 45$ $\mathrm{ms})$, not overlapping with any of the $\mathrm{S}$ or $U$ vowels The four $U$ vowels $(198 \pm 34$ $\mathrm{ms})$ are somewhat longer on average than the two $S$ vowels $(176 \pm 23 \mathrm{~ms})$, with some overlapping between the two groups A one-way analysis of variance shows the duration differences between $\mathrm{S}, \mathrm{U}$, and $\mathrm{L}$ to be highly significant, $\mathrm{I}(2,517)$ $=2871, \mathrm{p}<001$ Moreover, post hoc tests for contrasts indicate that the thiee length groups, S, U, and L, are signtficantly distinct from each other (New manKeuls test, $\mathrm{p}<05$ )

Regarding the effect of speech rate on overall duration, Figure 2 shows that all vowels, including diphthongs, vary systematically in duration, with more slowly pronounced vowels being longer than quickly spoken ones $(230 \mathrm{~ms}$ vs $203 \mathrm{~ms})$ One reason for the relatively small effect is that the female speaker was less sophisticated in observing speech rate instructions as compared to the male speaker, for whom the difterence was more appreciable (252 vs $205 \mathrm{~ms}$ for slow vs fast) Note that overlapping occurs between $S$ and $U$ monophthongs so that fast $U$ vowels have durations similar to their slow $S$ counterparts No such overlapping occurs between any of the $U$ vowcls and the1r $L$ counterparts

The effects of vowel quality on overall duration are presented separately for $\mathrm{S}$, $U$, and $L$ vowels in Figure 3

As a group, the monophthongs have durations of the same order of magnitude as the diphthongs, although the more open vowel $a$ is on average longer than $o$ This difference is most apparent in the L vowels An analy 1 s of vanance on monoph- 


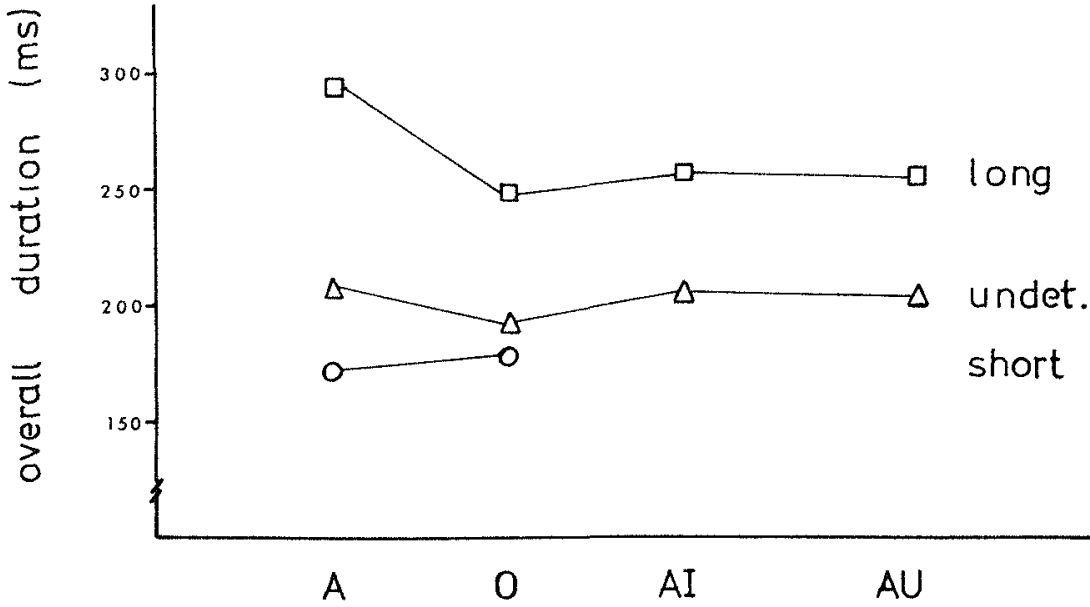

F1gure 3 Influence of vowel quality on overall duration for short, undetermined, and long pre-pausal vowels

thongs only shows that both the effects of length group, $\Gamma(2,317)=2589, p<001$, and of vowel quality, $\Gamma(1,318)=175, p<001$, reach significance, as does the interaction between these two factors, $F(2,314)=203, p<001$ Such an influence of vowel quality on duration is in accordance with the hterature where similar effects have been reported for a variety of langudges (for a survey, see Lehiste 1970 18ff) On the basis of this, we decided to pool our vowels into two groups, monophthongs vs diphthongs, for our subsequent analysis

Figure 4 shows the two pooled groups plotted in a two-dimensiondl plane, with the decay portion along the vertical axis and the initidl portion along the horizontal axis For the sake of clarity, no dispersion measures have been drawn in this graph This figure shows a clear separation into two clusters, one having decay times of 80 $\mathrm{ms}$ or less, the other of $105 \mathrm{~ms}$ or more The first cluster comprises $\mathrm{S}$ and $\mathrm{U}$ vowels, the second $\mathrm{L}$ vowels, with polar values for decay time most evident in monophthongs Within the first (lower) cluster, however, even the slight differences in decay time between $S$ and $U$ ( 72 vs $78 \mathrm{~ms}$ for monophthongs, $81 \mathrm{~ms}$ for $U$ diphthongs) prove to be significant by a Newman-Keuls test, $p<05$, following an analysis of variance, $F(2,517)=1839, p<001$ Thus $S$ vowels with glottal closure are statistically distinct from $U$ vowels with glottal closure, and both are distinct from $L$ vowels without glottal closure (decay time $114 \mathrm{~ms}$ ) These results confirm the preceding andlysis (Figure 3) showing three separate groups on the basis of overall duration

Within the $U$ vowels, diphthongs have the longest decay time, whereas within the $L$ vowels, diphthongs have the shortest decay time We would suggest that this lack of polarization along the decay time axis in diphthongs is due to their having no underlying length distinction, i e no targets exist for "short diphthongs", only "shorter" diphthongs An analysis of variance assessing the relative contribution of the factors (length group, monophthong vs diphthong, speech rate) on decay time vanation shows that the most significant effect is due to length group, $\Gamma(2,517)$ $=1852, \mathrm{p}<001$, with the monophthong vs diphthong difference being of lesser significance, $1(1,518)=142, p<001$, whereas the speech rate vanable proved insignificant, $\mathrm{F}(1,518)<1$ 


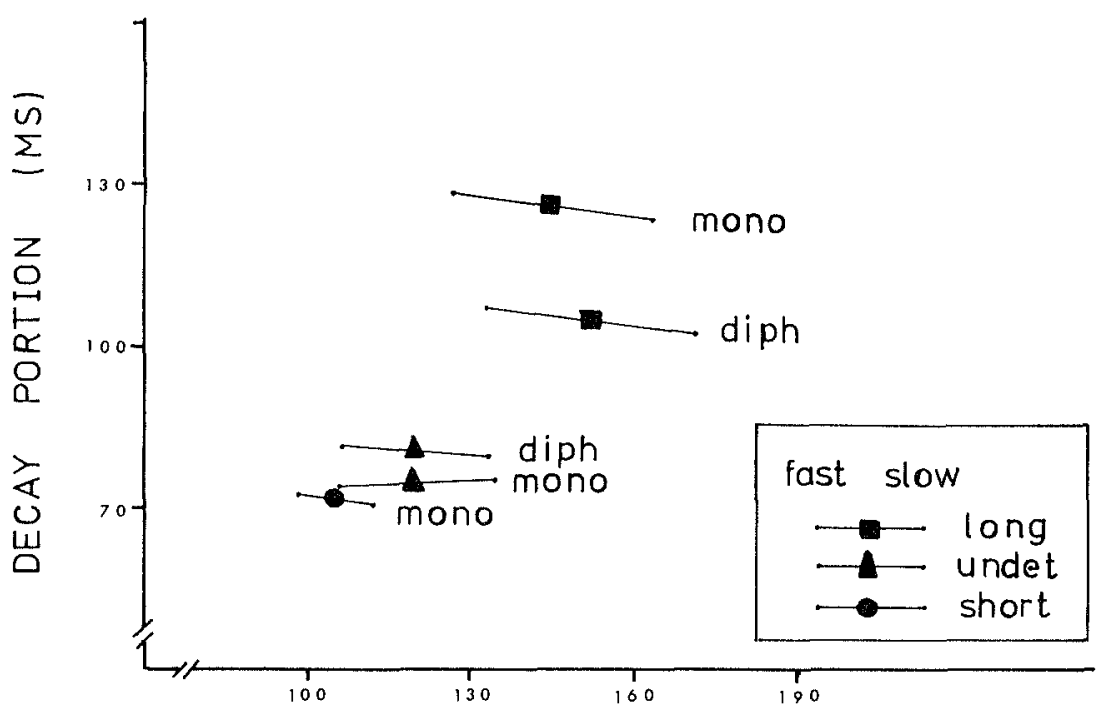

INITIAL PORTION (MS)

Figure 4: Means for short, undetermined, and long monophthongs and diphthongs, plotted in a two-dimensional decay portion/initial portion plane, separated out for fast and slow speech rates

In Figure 2, it is obvious that overall duration varies according to speech rate, with quickly spoken vowels being shorter. Figure 4 shows that time compression does not affect the two components, initial and decay, equally. In fact, decay time is remarkably unaffected by speech rate in all three length groups (see analysis of variance above). Instead, compression is achieved in the initial portion of all vowels, varying systematically from longer duration for slower speech to shorter duration for faster speech, with slight overlapping ranges between $S, U$, and $L$ vowels (refer to Appendix 2 for measurements). An analysis of variance shows that speech rate is the most important factor affecting variation of the initial portion, $F(1,518)$ $=121.8, \mathrm{p}<.001$. When the speech rate factor is averaged out, as shown by the filled centroids in Figure 4, then S, U, and L vowels form three distinct groups, having initial portion means at 105, 119, and $149 \mathrm{~ms}$, respectively.

\subsection{Experimental conclusions}

The evidence provides some clear answers to our original questions about the phonetic nature of U(ndetermined) vis-à-vis normal $\mathrm{S}$ (hort) and $\mathrm{L}$ (ong) pre-pausal vowels in Hausa. (1) $\mathrm{L}$ pre-pausal vowels are very definitely longer than S pre-pausal vowels, on the order of a $50 \%$ greater duration. Previous scholars (e.g. Greenberg 1942) have seriously underestimated the difference in duration. (2) $U$ monophthongs have short decay times very similar to $S$ monophthongs indicating that both groups 
end with glottal closure. (3) Although both S and U vowels have relatively short durations as compared to $\mathrm{L}, \mathrm{U}$ vowels as a class are consistently longer than $S$ vowels in both initial and decay portions. (4) Diphthongs are essentially comparable in temporal behavior to monophthongs. Most interestingly, $U$ diphthongs are not the same as $L$ diphthongs but are shorter and have glottal closure just like U monophthongs. (5) Differences in vowel quality produce no significant effects on the duration parameters, the four vowel types behaving as homogeneous sets within each of the three length groups.

To summarize, there are three statistically distinct phonetic categories of pre-pausal vowels: short duration with glottal closure, short-intermediate duration with glottal closure, and long duration without glottal closure.

\section{PHONOLOGICAL INTERPRETATION}

The preceding section has demonstrated that pre-pausal $U$ vowels are not $\mathrm{S}$ vowels but rather form a third phonetically distinct "intermediate" group. Before going on to the problem of interpretation posed by this fact, we would like to discuss the membership of the four cases where these "intermediate" vowels occur taken as a set (refer back to (5)).

The internal composition of this set is not as unnatural as it might appear. Cases $(b-d)$ do form a natural class: they are all verbs having an identical High* tone pattern. Our earlier statement that the length "alternation" was found only in "monosyllabic" or "Grade VI" verbs was a simplification. What really matters is that the verbs have High tone throughout, regardless of the number of syllables. This can be seen, for example, in the "pluractional" (= "intensive") forms of these verbs. ${ }^{11}$ The derived forms (e.g. shasshA, bibbiyA, kakkAI, sassaatO), which preserve the level High tone pattern, still exhibit the $U$ vowel pre-pausally. Thus, one can see that cases (b-d) are simply particular instances of a single class $\{z\}$, which is defined in terms of the lexical category Verb and the phonological tonal category High*. As for case (a), apart from its High tone, the pronoun has nothing particularly in common with the verbs. Nevertheless, since all U vowels have been shown to behave phonetically as a set, the case of the first person possessive pronoun should remain included even though this requires that the set be described in terms of disjunct grammatical categories. ${ }^{12}$

Turning now to the phonological question, a possible solution, which has been implicitly assumed by those Hausaists who recognize the existence of short variants, at least in cases (a) and (b), is that there is a morphophonemic rule whereby these particular long vowels become short prepausally. Then, all short vowels subsequently undergo a lower-level pho- 
netic rule specifying final glottal closure in pre-pausal position, e.g./daawoo/

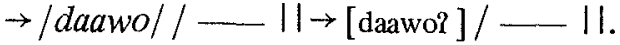

Given our findings, one must reject such a solution since it cannot explain the phonetic differences which were found between these shortened vowels and normal short vowels. Moreover, if one wants to account for all the cases in the same way, the solution requires the step of having to mark diphthongs as short in intermediate structure when nowhere else is such a specification ever needed.

Our interpretation is that $U$ vowels are long vowels ending with prepausal glottal closure. Their status is thus phonologically distinct from short pre-pausal vowels also ending with glottal closure. In our view, only one rule is needed, presented informally in (6):

$$
\begin{aligned}
& V \rightarrow {[\text { +glottal closure }] / \text { where } V \text { is (i) short, or } } \\
& \text { (ii) belongs to lexical class }\{a, z\}
\end{aligned}
$$

This rule says that final glottal closure is added pre-pausally whenever the vowel is either (i) phonologically short, or (ii) the long final vowel of a word belonging to one of the lexical classes listed as our cases (a-d), i.e. the first person possessive pronoun or a High tone verb. This solution is possible because we do not regard the presence of glottal closure as a phonetic feature integrally associated only with short vowels, as has been the standard analysis. ${ }^{13}$ Rather, it is considered as a prosodic feature of pausal position, having some kind of demarcative function. ${ }^{14}$ As such, it may be added either to short vowels, which is the usual case in Hausa, or to long vowels, which is much rarer. The actual shorter duration of the long vowels followed by glottal closure results from a phonetically natural process: it is a near-universal characteristic of any vowel checked by glottal stop that it is phonetically short in duration. In Hausa, the prepausal long checked vowels have nevertheless remained phonetically

\begin{tabular}{|c|c|c|c|c|c|}
\hline (7) & Long & Short & "Intermedi & & \\
\hline phon & doogo & kooko & rïgaataa & $z o o$ & \\
\hline & 'tall one' & 'grue & 'my gown' & 'come' & "clim \\
\hline$[P]$ addition & & kooko? & riigaataa? & $z 00 ?$ & hau? \\
\hline $\begin{array}{l}\text { phonetic } \\
\text { output }\end{array}$ & [do:go:] & [ko:ko?] & [ rì:ga:ta`?] & {$[\mathrm{zo} \cdot 2]$} & [ hău? ] \\
\hline
\end{tabular}
distinct from the short checked vowels. ${ }^{15}$ The following sample derivations illustrate the rule:

Our solution to the problem of $U$ vowels has emerged from the demonstration of the existence of a third phonetic category. Such a category 
had not previously been recognized because of certain commonly held ideas about Hausa: (1) presence of glottal stop was equated with short final vowels and absence of it with long final vowels; (2) differences in overall duration between long and short pre-pausal vowels were mistakenly minimized; and (3) the use of non-pausal contexts for determining phonological length of final vowels ruled out consideration of the existence of pre-pausal variants. The discovery of the third category has led to a revision of these ideas, in particular, the notion that there is a necessary one-to-one relation in Hausa between phonological length and pre-pausal glottal closure. At the same time, our solution does confirm the intuition of those scholars who transcribed $U$ vowels as long even though they acknowledged these as being phonemically short. Moreover, it coincides with what some linguistically sophisticated Hausa speakers have also felt about U vowels, which they have described as "not as short as short", "neither long nor short".

It is important to note that our interpretation of final glottal closure in Hausa as a pausal phenomenon rather than as a vowel length feature has direct parallels in other African languages. For example, in Fula (Arnott 1970), final glottality accompanies both long and short prepausal vowels as well as resonant consonants, but only for certain grammatical classes of morphemes. In Borana, a dialect of Oromo (Andrzejewski 1957), long pre-pausal vowels are realized as short plus glottal stop, remaining distinct from short pre-pausal vowels which are realized as voiceless. Finally, in Akan (Schachter and Fromkin 1968), phonetic glottal stop is one of the realizations of certain final vowels and resonants, but again, only in pre-pausal position. In the light of such phenomena, the existence in Hausa of certain long final vowels checked by pre-pausal glottal closure, as reported in this paper, does not seem so unusual. 
Appendix 1: The 26 Hausa test items recorded in pre-pausal position, listed according to final vowel and length group.

\begin{tabular}{|c|c|c|c|c|}
\hline & $\mathrm{A}$ & $\mathrm{O}$ & AI & $\mathrm{AU}$ \\
\hline \multirow{4}{*}{ SHORT } & $\begin{array}{l}\text { sàa ta } \\
\text { 'put it!' }\end{array}$ & $\begin{array}{l}\text { òoho } \\
\text { 'exclam.' }\end{array}$ & \multirow{4}{*}{\multicolumn{2}{|c|}{ (structurally empty) }} \\
\hline & $\begin{array}{l}\text { caaca } \\
\text { 'gambling' }\end{array}$ & $\begin{array}{l}\text { kooko } \\
\text { 'gruel' }\end{array}$ & & \\
\hline & $\begin{array}{l}P A \dot{A} b b a \\
\text { 'name (m)' }\end{array}$ & $\begin{array}{l}\text { Pìkko } \\
\text { 'geog. name' }\end{array}$ & & \\
\hline & $\begin{array}{l}\text { Kàaka } \\
\text { 'name (f)' }\end{array}$ & $\begin{array}{l}\text { Doogo } \\
\text { 'name (m)' }\end{array}$ & & \\
\hline \multirow[t]{2}{*}{$\begin{array}{l}\text { UNDETER- } \\
\text { MINED }\end{array}$} & $\begin{array}{l}\text { 'yaatA } \\
\text { 'my daughter' }\end{array}$ & $\begin{array}{l}\text { sàato } \\
\text { 'steal (and bring)!' }\end{array}$ & $\begin{array}{l}\text { tà } k A I \\
\text { ' that she carr }\end{array}$ & $\begin{array}{l}\text { tà } k A U \\
\text { "that she move aside" }\end{array}$ \\
\hline & $\begin{array}{l}\text { taa shA } \\
\text { 'she drank' }\end{array}$ & $\begin{array}{l}\text { Paiko } \\
\text { 'send (here)' }\end{array}$ & $\begin{array}{l}\text { taa } k A I \\
\text { 'she carried' }\end{array}$ & $\begin{array}{l}\text { taa } h A U \\
\text { 'she climbed' }\end{array}$ \\
\hline \multirow{3}{*}{ LONG } & $\begin{array}{l}\text { sàataa } \\
\text { 'stealing' }\end{array}$ & $\begin{array}{l}\text { Kòotoo } \\
\text { 'feeding' }\end{array}$ & $\begin{array}{l}\text { jàakai } \\
\text { 'donkeys' }\end{array}$ & $\begin{array}{l}\text { tàbàarau } \\
\text { 'eyeglasses' }\end{array}$ \\
\hline & $\begin{array}{l}\text { maataa } \\
\text { 'women' }\end{array}$ & $\begin{array}{l}\text { doogoo } \\
\text { 'tall one' }\end{array}$ & $\begin{array}{l}\text { yautai } \\
\text { 'nightjar' }\end{array}$ & $\begin{array}{l}\text { kibau } \\
\text { 'arrows' }\end{array}$ \\
\hline & & & $\begin{array}{l}\text { Laarai } \\
\text { 'name (f)' }\end{array}$ & $\begin{array}{l}\text { Jàatau } \\
\text { 'name }(\mathrm{m})\end{array}$ \\
\hline
\end{tabular}

Appendix 2: Duration measurements (in ms) for 10 Hausa vowel classes, recorded in pre-pausal position at slow vs. fast speech rates, with total means and standard deviations.

\begin{tabular}{|c|c|c|c|c|c|c|c|c|c|c|}
\hline Category & $\mathrm{N}$ & $\begin{array}{r}\text { Overall } \\
\text { slow/fast }\end{array}$ & 0 & & $\begin{array}{r}\text { Initial I } \\
\text { slow/fast }\end{array}$ & $\begin{array}{l}\text { ortion } \\
\text { mean }\end{array}$ & sd & slow/fast & $\begin{array}{l}\text { ortion } \\
\text { mean }\end{array}$ & sd \\
\hline SHORT & 160 & $183 / 170$ & 176 & 23 & $112 / 98$ & 10 & 21 & $71 / 73$ & 8 & 12 \\
\hline$a$ & 80 & $182 / 166$ & 174 & 23 & $13 / 96$ & 105 & 21 & $69 / 69$ & 9 & 12 \\
\hline$o$ & 80 & $184 / 174$ & 179 & 23 & $111 / 98$ & 105 & 21 & $73 / 76$ & 74 & 12 \\
\hline UNDET. & 160 & $211 / 184$ & 198 & 34 & 133 & 119 & 31 & $78 / 78$ & 78 & 19 \\
\hline$A$ & 40 & $226 / 183$ & 205 & 38 & $145 / 110$ & 128 & 32 & $82 / 73$ & 77 & 18 \\
\hline$o$ & 40 & $194 / 176$ & 185 & 32 & $123 / 99$ & 11 & 30 & $71 / 78$ & 4 & 14 \\
\hline$A I$ & 40 & 212 & 202 & 22 & $128 / 105$ & 117 & 27 & $84 / 86$ & 85 & 18 \\
\hline$A U$ & 40 & $214 / 186$ & 200 & 38 & $138 / 107$ & 123 & 30 & $77 / 78$ & 77 & 24 \\
\hline ONG & 200 & & 263 & 45 & 169 & 149 & 40 & $111 /$ & 114 & 30 \\
\hline$a a$ & 40 & $313 / 279$ & 296 & 46 & $167 / 133$ & 150 & 40 & $146 / 146$ & 146 & 33 \\
\hline oo & 40 & $263 / 232$ & 248 & 46 & $161 / 120$ & 140 & 49 & $102 / 112$ & 108 & 24 \\
\hline$a i$ & 60 & $275 / 240$ & 258 & 39 & $166 / 128$ & 147 & 39 & $109 / 112$ & 111 & 23 \\
\hline$a u$ & 60 & $275 / 237$ & 256 & 38 & $178 / 135$ & 156 & 38 & $97 / 102$ & 100 & 24 \\
\hline
\end{tabular}




\section{NOTES}

1 The term "glottal closure" is used expressly in this paper to refer to its function as a phonetic feature attributed to pre pdusal (short)final vowels This is to avold confusion with "glottd stop", which functions as a consonant in Hausd in prevocalic position

2 There are, of course, phonotactic restrictions affecting vowel length word-med1ally, e $g$ the occurrence of short vowels only in closed syllables, and the neutralizdtion of the length distinction between the high vowels before $/ y /$ and $/ w /$, but these are statable in terms of redundancy conditions rather than phonological rules

3 "Undetermined" vowels are written with capital letters to distinguish them from long vowels, written with double letters, and short vowels, written with a single letter

4 The verb $y O \sim w O$ 'do (and come)' $(\langle y l w O)$ could also be included here Some scholars, however, would treat it as a Grade VI verb, along with $s O$ and $z O$

5 The three disyllabic verbs in this group are considered to be members of the "monosyllabic" verb class on morphosyntactic grounds Note that the two monosyllabic verbs with falling tone, cee 'say' and saa 'put', are not subject to the alternation Other monosyllabic verbs such as baa 'give' and yaa (da) 'throw out', require a complement and never occur pre-pausally

6 Parsons (1961 106n) stated that the form of the linked pronoun was "na(a)/ta(a)", but he transcribed it throughout this article as short in all positions In a later article (1971/72), the pronoun was transcribed as long in all positions Jungraithmayr and Mohlig (1976) treated the pronoun as short everywhere, farling to note any contexts where it is long Unlike the first person, all other bound possessive pronouns do in fact have a short final vowel, e g $k a, k t, s a, t a, m u, k u, s u$

7 As proof of this, he shows that $O$ is long before the negative marker (his usual context for determuning final length), without realizing that it is then no longer in pre-pausal position

8 Carnochan mistakenly included biy $A$ among the High-High intransitive verbs having inherently short final vowels The shortening of jtrA and ktrA was brought to our attention by $\mathbf{P}$ Newman (personal communication)

9 Following the analysis in Newman and Salim (n d), monophthongs may be distinguished from diphthongs by a vowel feature such as [steady state] The feature [long] is then redundant for [-steady state] vowels, $1 \mathrm{e}$ diphthongs

10 Few experimental studies exist on vowel duration in Hausa and none on vowels in pre-pausal position Zima (1974) restricted himself to measured durations of a few $a$ and $o$ final verbs in non pausal position The earlier study by Hofmann (1964) presented relative durations in terms of overall short long ratios, taking tone somewhat into account, but ignoring position of the vowel within the word or phrase 11 The term "pluractional" is adopted from Newman and Sallm (n d) in preference to the more familiar but less accurate label "intensive" These verb forms normally indicate action performed a number of times or affecting a number of objects

12 This set may eventually contain more categories than presently recognized For example, the locative form (a) kaa 'on the head' (cf kal 'head') also exhibits final glottal closure pre-pausally

13 Carnochan very clearly regards glottal prosody as the defining feature of short vowels generally, in his system, even non-final syllables containing short vowels have the structure CV?-(1952 96-97)

14 The idea that the glottal closure in Hausa is a pausal feature serving to mark off the end of certain utterances is further supported by the fact that in interrogative sentences, final [?] is not present, neither after structurally short vowels nor after $U$ vowels (Newman and Newman 1981)

15 It would not, however, be surprising to find this distinction being lost by some Hausa speakers Measurements of a small sample of pre-pausal $U$ and $S$ vowels recorded by a speaker from Bauch1 showed that while his $U$ vowels tended to be longer than his $\mathrm{S}$ vowels, the differences in duration were much smaller than those reported in our present experment 


\section{REFERENCES}

Abraham, RC 1959 The Language of the Hausa People London University of London Press

Andrzejewskı, B W 1957 Some preliminary observations on the Borana dialect of Galla BSOAS 1935474

Arnott, D W 1970 The Nominal and Verbal Systems of Fula London Oxford University Press

Broecke, M P R van den, and V J van Heuven 1981 Fact and artifact in the auditory discrimination of rise and decay time Prog Report of the Institute of Phonetics Utrecht 6 (2) (1n press)

Carnochan, J 1951 A study of quantity in Hausa BSOAS 13 1032-44

1952 Glottalization in Hausa In Transactions of the Phlological Society, pp 78-109 London

Cohen, A, I H Slis, and J 't Hart 1963 Perceptual tolerances of 1solated Dutch vowels Phonetica 9 65-78

Cowan, J R, and R G Schuh 1976 Spoken Hausa Ithaca NY Spoken Language Services

Debrock, M 1977 An acoustic correlate of the force of articulation $J$ Phonetics 56180

Gouffé, C 1965 La lexicographie du haoussa et le prealable phonologique $J$ Afr Lang 4 191-210

- 1974 Review of Hausa by Kraft \& Kirk-Greene Bull Soc Ling de Parts 69 (2) $392-401$

1977 Review of Spoken Hausa by Cowan \& Schuh Bull Soc Ling de Parts $72(2) 378-86$

Greenberg, J H 1942 Some problems in Hausa phonology Language 17 316-23

Heuven, V J J P van, and M P R van den Broecke 1979 Auditory discrimination of rise and decay times in tone and norse bursts $J$ Acoustlc Soc America 66 120815

Hodge, C T, and I Umaru 1963 Hausa Basıc Course Washıngton, D C Foreign Service Institute

Hofmann, I 1964 Das Verhaltnıs der Langvokale zu den Kurzvokalen im Hausd Afr $u$ Ubersee 48 202-11

Jungrathmayr, H, and W J G Mohlig 1976 Einfuhrung in die Hausa-Sprache (Marburger Studien zur Afrika- und Asıenkunde, Serie A Afrika, 7 ) Berlın Dietrich Reimer

Kraft, C H and A H M Kirk-Greene 1973 Hausa (Teach Yourself Books) London The Cngl_sh Universities Press

Kozhevnikov, V A, and C A Chistovich 1965 Speech Articulation and Perception (Moscow Leningrad) Trans by Joint Publications Research Services, Washington, D C , JPRS 30543

Lehiste, I 1970 Suprasegmentals Cambridge, MA MIT Press

Malécot, A 1975 The glottal stop in French Phonetıca 31 51-63

Newman, P, and R M Newman 1977 Modern Hausa English Dictionary Ibadan \& Zana Oxford University Press

1981 The question morpheme q in Hausa $A$ fr $u$ Ubersee 64 (in press)

Newman, P, and B A Salim $\mathrm{n} d$ Hausd diphthongs Lingua (in press)

Parsons, H W 1960 The verbal system in Hausa Afr $u$ Ubersee 44136

1961 The operation of gender in Hausa the personal pronouns and genitive copula Afr Lang Studies 210024 
1971/72. Suppletion and neutralization in the verbal system of Hausa. Afr. $u$. Ubersee 55:49-97, 188-208.

Schachter, P. and V. Fromkin. 1968. A Phonology of Akan: Akuapem, Asante and Fante. (Working Papers in Phonetics, 9.) Los Angeles: UCLA.

Zima, P. 1974. Final vowel duration of grade 6 verbs in Hausa (a phonetic problem with grammatical implications). Asian and Afr. Studies [Bratislava] 10:49-59.

Department of African Linguistics and Department of Linguistics/Phonetics Laboratory University of Leiden 